Journal of Computer Science 2 (4): 382-387, 2006

ISSN 1549-3636

(c) 2006 Science Publications

\title{
Optimization of an Automatic Blast Furnace through Integrated Simulation Modeling
}

\author{
Ali Azadeh, Ph.D. and S. Farid Ghaderi, Ph.D. \\ Department of Industrial Engineering, Research Institute of Energy Management and Planning \\ Department of Engineering Optimization Research, Faculty of Engineering \\ University of Tehran, P.O. Box 11365-4563 Iran
}

\begin{abstract}
The objective of this study was to develop an integrated simulation model of an automatic blast furnace in a full-scale steelmaking factory. The integrated simulation model introduces a set of optimizing alternatives through sensitivity analysis. The simulation model is built by considering all major and detailed operations and interacting systems of the blast furnace workshop. The workshop is composed two parallel blast furnace each containing of a joint raw material storage and furnace and cast-iron stations. Furthermore, there are 54 operations for each blast furnace workshop. The results and the structure of the integrated simulation model were verified and validated by comparative analysis and t-test. Moreover, the monthly production rate of cast-iron station is chosen as the performance measure for the actual system and simulation model in a twelve months trial. The results of t-test shows the average monthly production of cast-iron for the two system is statistically equal (at $\alpha=0.05$ ). Also, the industrial engineering unit and the production managers accredited the integrated model. After this stage, the simulation was run for a period of six months to evaluate major bottlenecks in the system. Finally, two optimizing alternatives, which can save the company millions of Dollars, are introduced and their economic advantages are discussed. The integrated simulation model has several unique features. First, it is integrated and considers all operations, maintenance, repairs, quality control activities, systems' limitations and interaction with other systems. Second, it is coded in parametric fashion so any alternative may be easily retrieved. Third, it is a practical tool due to its verification, validation and accreditation. Finally, a standard procedure for development of integrated simulation model for similar blast furnace or workshops is introduced.
\end{abstract}

Key words: Integrated, simulation, blast furnace, optimization, modeling, verification, validation

\section{INTRODUCTION}

Computer simulation is one of the most advanced and powerful tools in system analysis. It is an exquisite tool for modeling and analyzing the true performance of manufacturing systems. A computer simulation would allow the designers of manufacturing systems to predict and provide the means to control the relevant disturbances to an acceptable degree of completeness. The simulation approach would enable the designers and analysts to foresee the behavior of such systems in normal and also emergency situations. Furthermore, it enables the system designers to decide on the optimal numbers of machines, workstations, resources, human operators and the acceptable workload level ${ }^{[1-3]}$. Undoubtedly, simulation approach leads to a smoother and more efficient performance for such systems. In highly industrialized countries, computer simulation has become one of the most widely used techniques for evaluation of systems' performance.

The advantages of steel plant (blast furnace, casting and rolling mill) simulation are improved yield, productivity and efficiency ${ }^{[4,5]}$. An optimizing tool, which uses an inverse modeling approach to determine input parameters given the experimental results is introduced $^{[6]}$. The author contends that a number of input parameters to casting simulation software (such as material properties and boundary conditions) are not well known. The optimal operating conditions for the primary end of an integrated steel plant is modeled through a genetic adaptive search and by classical techniques of simplex search with simulated annealing and sequential quadratic programming ${ }^{[7]}$. There are several studies that concentrate on simulation modeling of steel plants, casting and rolling mills ${ }^{[8-17]}$. This study presents a total modeling and simulation approach for simulation of large blast furnace workshops. The objective of this type of modeling is to simulate the entire activities and processes rather than zooming at a particular aspect of the workshop. Furthermore, the prescribed approach advocates total picture modeling even if the objective of the study may be related to a particular station in the workshop. This is because many stationary issues (bottlenecks) are affected by total system parameters. The unique feature of this study is integrated modeling and optimization of a large system by computer simulation. This study emphasizes on the total optimization of a large blast furnace

Corresponding Author: Ali Azadeh, Ph.D., Department of Industrial Engineering and Research Institute of Energy Management and Planning, Faculty of Engineering, University of Tehran, P.O. Box 11365-4563, Iran 
workshop through an integrated computer simulation methodology. Also, the model is designed such that it could be integrated with other workshops of the factory such as rolling mill and casting. Moreover, it is capable of driving to optimum solutions by a rule-based mechanism.

The workshop: The workshop is composed of two blast furnaces in a full-scale steel factory. The required raw materials are coke, agglomerate coal, ironstone and other material aids. The output products of the workshop are cast iron, slag and furnace gas. The required raw materials for the first and second furnace are stored in bunkers 0 to 23 and bunkers 1 to 16 , respectively. Static (KD) and dynamic (RKD) conveyors fill all bunkers except bunker 0 . KD does the process of transferring raw material from storage rooms to RKD and the operation of unloading raw material is done by RKD. Two skips are used to transfer material (ironstone, coke and agglomerate) from bunkers to furnace number 2. Moreover, while one is loading the furnace the other one is unloading and the material is transferred to the top portion of the furnace (on the small bell). The small bell is opened if the following conditions are met:

* There should exist pressure equilibrium

* The large bell must be opened and closed when unloading the first skip from each load;

* The separation pump must have completed its flow

By opening the small bell the raw material is transferred to the large bell. Also, several conditions must be met to open the large bell, which are:

* Four skip needs to be available on the large bell;

* There should exist pressure equilibrium;

* A space with height of 1.5 to 2.5 meters (usually 1.75) must be available;

* The first skip from the next load on the small bell must be available

When the large bell is opened the total load is feeded to the furnace. Hot air with the temperature of 1000-1100 Celsius and the pressure of 2.5-3.0 Atmospheres is blown into furnaces. After achieving a certain level of hot cast inside the furnace, the furnace is unloaded through external doors. Then, cast iron and slag are separated by separator pumps (siphon) and are transferred to appropriate (cast iron or slag) ladles via canals. The canals are cleaned after each unloading and every 10 days their coatings are replaced. Also, the canals are replaced every 30 days. If all canals are broken, the production rate of cast iron is reduced and one of the canals is at least temporarily repaired and prepared. There are two rails (numbered 3 and 4) for loading the cast iron ladles and each rail is equipped with a wagon (pusher) with three 80-tons ladles attached to it. After slag and cast iron are separated by separation pump (siphon), they are entered into the tub

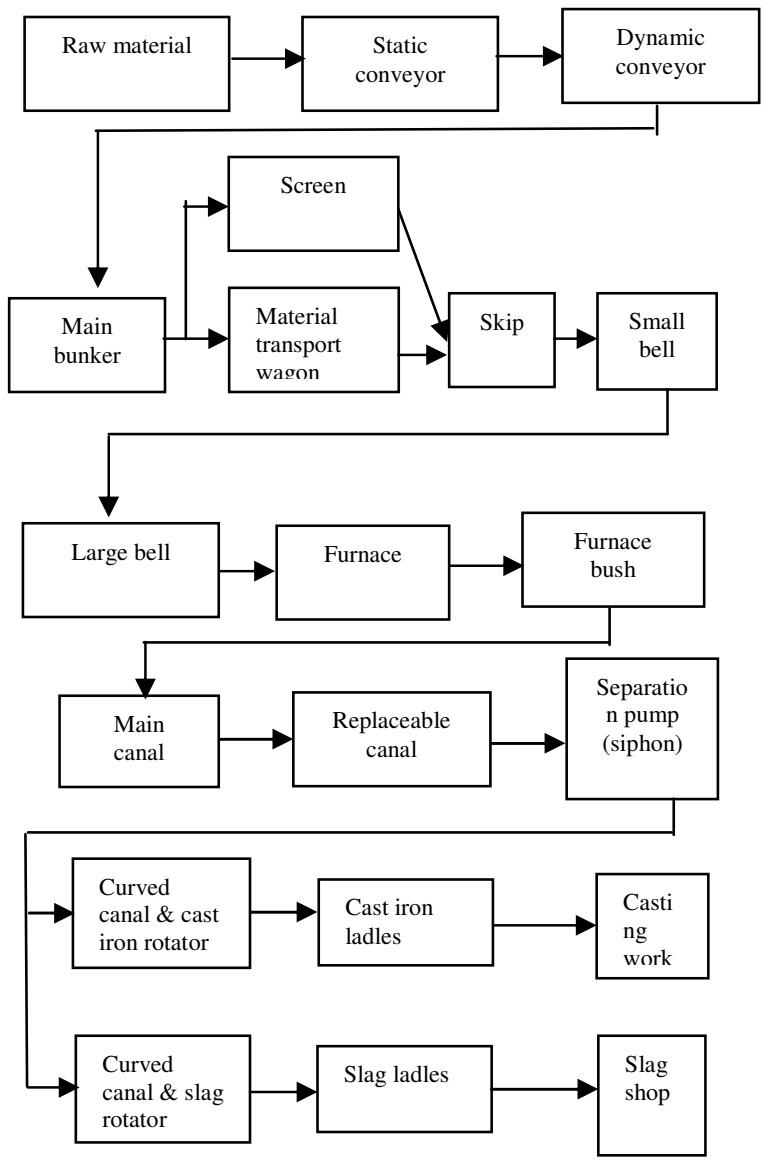

Fig. 1: Material flow chart of the blast furnace

by curved canal. The tub is capable of unloading material to its left and right side empty ladles. The loaded submarine ladles are transferred by railed wagons number 1 and 2 to casting workshop. Station technical sheets are designed to illustrate the main characteristics of each workstation. Some stations contain several equipment, in such cases additional sheets are designed for each of them. These sheets provide detailed information about workstations and are necessary for development of the integrated simulation approach discussed in this study. An example of station technical sheet is shown in Table 1 .

Table 1: A sample of station technical sheet

\begin{tabular}{lll}
\hline Station name: Storage & Blast Furnace I & Station No: 1001
\end{tabular}

Equipment: Static and dynamic $\quad$ Bunkers capacity (ton): $\quad$ Bunkers No: 1-23 conveyors and bunkers $1650,1000,200,590$

Equipment technical information: The static conveyors are used for loading and dynamic conveyors are used for unloading. Also, dynamic conveyors are capable of unloading in various bunkers or transfer material to the following conveyors.

Input: coke, agglomerate coal, ironstone and other material aids

Output: without change

Mission of operation: storage of material for feeding blast furnace I. Operation description: agglomerate coal is received from agglomeration. Ironstone and material aids are received from storage and coke is received from coke workshop. Coke bunkers are transferred to dynamic conveyors by static conveyors and are then loaded into particular bunkers by the rails. 
Integrated model: Our approach of simulation modeling is somewhat different than traditional methodology. Considering the complexity of the system being studied, the following steps must be passed to reach a useful, integrated and optimizer model. Item 5 is added to create integration mechanism of the simulation. This allows detailed description of the workshop and its interaction with all other workshops. Item 7 is added to make the model applicable. This is done through a series of presentations, interviews and feedback sessions with production managers and senior engineers. Item 8 allows optimization of the system through a set of if then questions.

* Problem definition and formulation.

* Develop conceptual models.

* Data collection and analysis.

* Build the model.

* Create the integration mechanism.

* Verify and validate the model.

* Accredit the model by production managers

* Analyze the results through a rule-based mechanism.

* Introduce the optimum solutions.

Visual SLAM (Awesim) language was used to build the model ${ }^{[18]}$. In order to simplify and integrate the model and increase its flexibility, it is made of 12 different networks and each network represents an aspect of the production process. Table 2 shows the list of these networks and their functions. Maintenance network is designed to define the downtimes caused by failures and maintenance. Furthermore, an entity is created and the characteristics of the first downtime are assigned to it as attributes. These characteristics include the failure time and duration. Then, the entity makes the station unavailable at the predefined interval and after the failure period it makes the station available again. Afterwards, the entity gets next failure characteristics and starts a new loop.

Each network has a unique reference code. For example the Awesim definition of KH101 which is shown in Table 3 represents the required nodes for the arrival of raw material into the workshop. The raw materials including coke, agglomerate coal, ironstone and other material aids are arrived in the storage area with RLOGN (3.87, 0.10), RNORM (3.84, 0.70), RLOGN $(3.83,1.59)$ and RLOGN $(3.15,1.47) \mathrm{min}$, respectively. The raw materials are classified into iron (agglomerate coal, ironstone and other material aids) and coke materials. The traverse time by a wagon to fill up a skip with iron material is normally distributed with RNORM $(2.37,0.54)$. The time to fill up a skip with coke material is Lognormaly distributed with RLOGN $(3.87,0.10)$. The loading of iron and coke material into a skip is 0.10 and $0.42 \mathrm{~min}$, respectively. A loaded skip is moved toward the top portion of the furnace by an elevator, which takes about one minute. If the small bell is empty through assessing its status by the control point, it continues its movement. Otherwise, it is stopped in the control point until the small bell is empty. If the small is empty, the raw materials are unloaded on the small bell and skip is ready to return to the bunker area. If the conditions discussed earlier is achieved the small is opened for unloading into large bell for about $0.42 \mathrm{~min}$. Then, the large bell is opened if the conditions discussed before are satisfied. It then feeds $(0.83 \mathrm{~min})$ the material into the furnace. Furnace has a capacity of 52 loads and each load waits in the queue until receiving service which is converting them into cast iron and slag) with RLOGN $(7.56,0.43) \mathrm{min}$. The cast iron and slag are then moved to the bush area of the furnace. A mathematical expression is used to define the share of cast iron from each load. The furnace is unloaded after a time interval, which is a lognormal random variable with RLOGN $(116,22.28)$. This time includes the time for availability of railed wagons, ladles, canals and other required resources. The unloading time is log normally distributed with RLOGN (55.24, 11.10) min. This time includes separation of cast iron and slag and removing them into railed wagon by the canals. The cast iron and slag ladles have the capacity of 75 and 28 tons, respectively. The ladles are transferred to casting and slag workshops through railed wagons. The traverse time (round trip) of delivering cast iron and slag by railed wagons to casting and slag workshops are RNORM $(58.28,12.84)$ and RLOGN $(83.13,13.53)$, respectively. The waiting time for return of empty ladles to the blast furnace area is RNORM $(125,28.19)$ and RLOGN $(83.13,13.53)$ for cast iron and slag, respectively. The time between failure in the blast furnace I is EXPON (6.59) and time to repair is RLOGN $(5.39,6.22)$. Also, the time between failures and time to repair of cast iron and slag ladles are modeled into the integrated simulation.

The model is developed such that it could be integrated with other workshops in the factory. Moreover, each of the workshops should be simulated and then considered as a workstation. The characteristics each of the workstations can be retrieved from this model and used for the whole factory model.

Verification and validation: Monthly production rate of cast iron in the workshop is chosen as the main criteria for validation of the simulation model. Two main reasons support the validity of monthly production rate. First, the production rate of the blast furnace workshop is the most important criteria in evaluation of this system. Second, this criterion can be easily measured both in the real system and simulation model. The required information is retrieved from monthly reports of the workshop and estimated statistics in COLCT node of Visual Slam.

The simulation was run for 1 month and repeated 12 times (Table 4). Measured values were examined by the t-test for the simulation and the actual system. 
Table 2: Network models of the workshop

Code Network definition

KH101 Arrival of raw material to the loading of skips (furnace I)

KH102 Transfer of skips to the top portion of furnace and arrival of slag and cast iron to the furnace gas (furnace I)

KH103 Transfer of cast iron ladles to the casting workshop and vise versa (furnace I)

KH104 Transfer of slag to the slag workshop and vise versa (furnace I)

KH105 The mechanism for opening and closing of furnace external door and proper actions to transfer ladles (furnace I)

KH201 From the arrival of raw material to the loading of skips (furnace II)

KH202 Transfer of skips to the top portion of furnace and arrival of slag and cast iron to the furnace gas (furnace II)

KH203 Transfer of cast iron ladles to the casting workshop and vise versa (furnace II)

KH204 Transfer of slag to the slag workshop and vise versa (furnace II)

KH205 The mechanism for opening and closing of furnace external door and proper actions to transfer ladles (furnace II)

KH300 Repair and preventive maintenance for furnace I and II

KH400 Defined resources in all the above networks

Table 3: Awesim description of KH101 and KH102 networks

\begin{tabular}{|c|c|c|}
\hline$\overline{\text { Code }}$ & Node & Description \\
\hline K1011 & CREATE & Arrival of agglomerate \\
\hline K1012 & CREATE & Arrival of ironstone \\
\hline K1013 & CREATE & Arrival of material aids \\
\hline K1014 & ACCUMULATE & $\begin{array}{l}\text { Accumulation of each two } \\
\text { agglomerate into one for } \\
\text { loading into wagon }\end{array}$ \\
\hline K1015 & ACCUMULATE & $\begin{array}{l}\text { Accumulation of each two } \\
\text { ironstone into one for loading } \\
\text { in wagon }\end{array}$ \\
\hline K1016 & ACCUMULATE & $\begin{array}{l}\text { Accumulation of each two } \\
\text { material aids into one for } \\
\text { loading purpose }\end{array}$ \\
\hline K1017 & QUEUE & $\begin{array}{l}\text { The logic for material request } \\
\text { by wagons from bunkers }\end{array}$ \\
\hline K1018 & QUEUE & Agglomerate bunkers \\
\hline K1021 & GOON & $\begin{array}{l}\text { Start of skip's movement } \\
\text { toward the top portion of } \\
\text { furnace }\end{array}$ \\
\hline K1022 & GOON & $\begin{array}{l}\text { Control point and decision- } \\
\text { making logic about movement } \\
\text { of skips }\end{array}$ \\
\hline K1023 & ACTIVITY & $\begin{array}{l}\text { Continuation of skip } \\
\text { movement given small bell is } \\
\text { empty }\end{array}$ \\
\hline K1024 & QUEUE & $\begin{array}{l}\text { The logic of skip waiting } \\
\text { given small bell is not empty }\end{array}$ \\
\hline K1025 & SERVICE ACTIVITY & $\begin{array}{l}\text { Skip stoppage time in control } \\
\text { point until small bell is ready }\end{array}$ \\
\hline K1026 & GOON & $\begin{array}{l}\text { Start of skip's movement } \\
\text { toward the top portion of } \\
\text { furnace }\end{array}$ \\
\hline K1027 & ASIGN & $\begin{array}{l}\text { Assigning a skip number for } \\
\text { each load }\end{array}$ \\
\hline K1028 & GOON & $\begin{array}{l}\text { The logic of assessing the } \\
\text { status of large and small bells }\end{array}$ \\
\hline
\end{tabular}

The test has proved the statistical similarity between the model and the system throughputs. Furthermore, from the $\mathrm{t}$-test it is concluded that the average monthly production rates for blast furnace (number 1 and 2) and simulation model are statistically equal (at $\alpha=.05$ ). The comparisons of the monthly production rates of cast iron for the two blast furnaces are shown in Tables 5 and 6 . The equality of variance was tested prior to the ttest $^{[19,20]}$.

Table 4: Monthly productions of cast iron for simulation and the workshop

\begin{tabular}{|c|c|c|c|c|}
\hline \multirow[b]{2}{*}{ Month } & \multicolumn{2}{|c|}{ Blast furnace number 1} & \multicolumn{2}{|c|}{ Blast furnace number 2} \\
\hline & Actual system & Simulation & Actual system & Simulation \\
\hline February & 65677 & 59534 & 112906 & 116029 \\
\hline March & 58370 & 61360 & 113575 & 114550 \\
\hline April & 64411 & 61351 & 118848 & 119206 \\
\hline May & 53707 & 61327 & 117838 & 119655 \\
\hline June & 54092 & 61300 & 116853 & 119163 \\
\hline July & 62871 & 58999 & 116674 & 119179 \\
\hline August & 59713 & 61245 & 115300 & 117161 \\
\hline September & 64755 & 60342 & 115723 & 111754 \\
\hline October & 63264 & 61385 & 121153 & 117707 \\
\hline November & 63889 & 58278 & 124144 & 119789 \\
\hline December & 63780 & 61299 & 122974 & 119620 \\
\hline January & 58489 & 61141 & 118732 & 119684 \\
\hline
\end{tabular}

Table 5: Two-sample analysis results of the blast furnace I and simulation model

\begin{tabular}{|c|c|c|c|c|}
\hline & No. of Obs. & $\begin{array}{l}\text { Av. monthly } \\
\text { production } \\
\text { (tons) }\end{array}$ & SD & t-test \\
\hline Blast furnace I & 12 & 61084.8 & 4134.23 & Sig.Level $=0.716$ \\
\hline Simulation & 12 & 60630.1 & 1092.15 & \\
\hline
\end{tabular}

$\mathrm{SD}=$ standard deviation

Table 6: Two-sample analysis results of the blast furnace II and simulation model

\begin{tabular}{|c|c|c|c|c|}
\hline & No. of Obs. & $\begin{array}{l}\text { Av. monthly } \\
\text { production } \\
\text { (tons) }\end{array}$ & SD & t-test \\
\hline Blast furnace II & 12 & 117791 & 2534.57 & Sig.Level $=0.936$ \\
\hline Simulation & 12 & 117893 & 3498.83 & \\
\hline
\end{tabular}

$\mathrm{SD}=$ standard deviation

Model analysis: The simulation model was run for a period of six months. After the simulation run the conditions of workstations are monitored. Average utilization of cast iron and slag ladles are $42 \%$ and $47 \%$ respectively. Also, cast iron and slag ladles are down due to repair and maintenance $19 \%$ and $20 \%$ of the time respectively. Average waiting times of cast iron and slag to be loaded into ladles is relatively high. Therefore, by sensitivity analysis and in order to reduce waiting times, optimum number of cast iron and slag ladles are analyzed and introduced. Both furnaces are busy 97 percent of the time. Major bottlenecks of the workshop are shown in Table 4. Because of blocked skips, small and large bells and average waiting times of each load, the blast furnace number 1 and 2 are the bottlenecks and therefore their conditions are analyzed next. Three alternatives are examined. First, the impact of an additional furnace is examined. Second, the impact of increasing production rates of cast iron (alternative 2) and slag due (alternative 2) to introduction of better technology and raw material is examined.

The first alternative is not justified because it is rather a developmental plan than a plan for balancing the workshop. Furthermore, it requires introduction of a blast furnace and supporting resources such as raw 
Table 7: Major bottlenecks of the blast furnace

\begin{tabular}{llll}
\hline Blast furnace No. & \multicolumn{3}{l}{ Percent idleness due to blocking effect } \\
& - Skips & Small bell & Large bell \\
\hline I & 32 & 33 & 22 \\
II & 12 & 20 & 9 \\
\hline
\end{tabular}

material and transportation system. The second alternative balances the material flow between first (loading raw material) and second stations (slag and cast iron production) through introduction of better technology and raw material (hypothetical). Furthermore, the ratio of average loading rate to average unloading rate in the furnace (1 to $1.5 \mathrm{~min}$ ) is increased. This is achieved through increasing production rate by .5 (alternative 2) and $1 \mathrm{~min}$ (alternative 3).

To implement the above alternatives (2 and 3), system's capability in respect to increasing the production rates of cast iron and slag must be evaluated. Then by implementing these constraints in simulation, the required resources and production improvements are identified (Table 8). Finally, by considering the total costs, incomes and net profit of a particular alternative is justified for implementation as follows:

$\mathrm{C}_{1}=$ Cost of increasing the production rates of cast iron and slag

$\mathrm{R}_{1}=$ Total income by increasing the production rates of slag and cast iron

$\mathrm{C}_{2}=$ Cost of required resources such new ladles, etc.

$\mathrm{R}_{2}=$ Income from utilizing in other workshops such as casting and rolling mill workshops

$\mathrm{B}=\left(\mathrm{R}_{1}+\mathrm{R}_{2}\right)-\left(\mathrm{C}_{1}+\mathrm{C}_{2}\right)=$ Net profit

$\mathrm{MB}=$ Minimum required profit

Therefore, the decision criteria for implementation of the above alternatives is when $\mathrm{B}>\mathrm{MB}$.

Table 8: The impacts of increasing the production rate by introduction of better technology and raw material in a six months period

\begin{tabular}{|c|c|c|c|c|}
\hline \multirow{2}{*}{$\begin{array}{l}\text { Production increase } \\
\text { /required resources }\end{array}$} & \multicolumn{2}{|c|}{ Alternative 2} & \multicolumn{2}{|c|}{ Alternative 3} \\
\hline & Furnace I & Furnace II & Furnace I & Furnace II \\
\hline $\begin{array}{l}\text { Cast iron production } \\
\text { increase (tons) }\end{array}$ & 17421.77 & 64809.90 & 54065.84 & 73753.70 \\
\hline $\begin{array}{l}\text { Slag production } \\
\text { increase (tons) }\end{array}$ & 14020.70 & 52436.60 & 43770.25 & 59359.10 \\
\hline $\begin{array}{l}\text { Required additional } \\
\text { cast iron ladles }\end{array}$ & & & & 7 \\
\hline $\begin{array}{l}\text { Required additional } \\
\text { slag ladles }\end{array}$ & & & & 9 \\
\hline
\end{tabular}

\section{CONCLUSION}

A complex blast furnace workshop was analyzed and optimized using an integrated simulation approach. The model was built using the Awesim simulation software. The model was verified, validated and accredited using robust statistical and structural analysis. The pros and cons of three distinct alternatives were discussed. The first alternative is left for development phase of the workshop in the future. Moreover, this alternative which is concerned about introduction of a new blast furnace was discarded from further consideration because it is actually a development plan for the factory. The second and third alternatives are proven to be efficient and economical for the workshop in the long run. In fact, the management is very keen to implement the results of integrated simulation in the near future.

The simulation model is designed such that it may be easily integrated with other workshops of the factory. Using the integrated computer simulation methodology has several benefits for the workshop as follows:

* The model is integrated and considers the detailed activities of the workshop. Also, this mechanism allows for integration of the blast furnace with other workshops such as casting and rolling mill.

* The simulation methodology locates major bottlenecks in the system.

* The model was accredited by production managers and is on the stage of implementation.

* The effects of specific parameters such as increased demand can be easily analyzed by changing them and repeating the simulation run.

\section{REFERENCES}

1. Azadeh, M.A. and K. Jalali Farahani, 1998. Successful implementation of computer simulation in industrial plants. Foolad (Steel) J., 46, Isfahan, Iran.

2. Azadeh, M.A., 1999a. An intelligent computer simulation framework for modeling assembly shops. Proc. 26th Intl. Conf. Computers and Industrial Engineering. Dec., Melbourne, Australia.

3. Azadeh, M.A., 1999b. Verification, validation and accreditation of simulation projects: A case study. Sanaye (Industrial) J., Sharif Univ. of Technology, Tehran, Iran. (3503).

4. Kevin, S., 1995a. Casting simulation's contribution to improved yield. Foundry Trade J., 169.

5. Kevin, S., 1995b. Casting simulation: A must, not a maybe, for optimum casting design. Foundryman, 88: 2 .

6. Singh, D., 2001. Applications of optimization in metal casting. Intl. J. Vehicle Design, 25: 1-2.

7. Deo, B. et al., 1998. Optimal operating conditions for the primary end of an integrated steel plant: Genetic adaptive search and classical techniques. ISIJ Intl., 38: 1.

8. DeJohn, F.A. et al., 1980. The use of computer simulation programs to determine equipment requirements and material flow in the billet yard. Proc. AIIE Spring Annual Conf. 
9. Todd, P.N., 1984. Simulation for steel plant design and planning. Proc. Steelmaking Meeting, Paris, France.

10. Naganuma, Y. et al., 1986. Some steelmaking process simulations and their applications. Proc. Conf. Automation in Mining, Mineral and Metal Process., Tokyo, Japan, 24-29 Aug.

11. Shevchenko, A.D. et al., 1989. Evaluation of operation of an electric steelmaking shop with the aid of simulation modeling. Byelorussian Metallurgical Works, Siberian Metallurgical Institute, STAL (6), June, pp: 89-91.

12. Stover, W.D. and K. Mabrouk, 1991. Scheduling steelmaking with simulation. Manufacturing Systems, 9: 58-61.

13. Hintikka, S. et al., 1992. Optimization of molten steel flow in continuous casting mold. Proc. Steelmaking Conf., Toronto, Canada, 5-8 April.

14. Pegden, C.D., 1993. Simulation in the steel industry: Past, present and future. Proc. Computerized Production Control in Steel Plant, Korean Institute of Metals and Materials, Seoul, South Korea.
15. Currey, D., 1995. Optimization of casting speed for higher productivity on Dfasco's No. 1 continuous caster. Steelmaking Conf. Proc., Vol. 78, Nashville Tennessee, USA.

16. Chang, K.S. et al., 1996. Dynamic modeling of LD converter processes. Research Institute of Industrial Science and Technology, Technical Research Report 5(2), Seoul, South Korea, June.

17. Azadeh, M.A., 1999d. An algorithm for accomplishment of simulation projects in developing countries: The case of an assembly shop. Proc. Intl. Conf. Reliability, Maintainability and Safety, Shanghai, China.

18. Pritsker, A.A.B. et al., 1997. Simulation with Visual Slam and Awesim. New York: Wiley and Sons.

19. Montgomery, G., 1985. Design and Analysis of Experiments. New York: Wiley and Sons.

20. Azadeh, M.A. and M. Dashtabadi, 1999c. Production planning through computer simulation in a complex job shop. Ravesh (Method) J., No. 52, Tehran, Iran. 